\title{
Air quality and chronic disease: why action on climate change is also good for health
}

\author{
Martine Dennekamp ${ }^{\mathrm{A}, \mathrm{C}}$ and Marion Carey ${ }^{\mathrm{B}}$ \\ ${ }^{\mathrm{A}}$ Monash Centre for Occupational and Environmental Health, \\ Monash University \\ ${ }^{\mathrm{B}}$ Monash Sustainability Institute, Monash University \\ ${ }^{\mathrm{C}}$ Corresponding author. Email: martine.dennekamp@ \\ med.monash.edu.au
}

\begin{abstract}
There is increasing evidence that air pollution contributes to the burden of chronic disease and premature mortality, particularly from cardiovascular and respiratory causes. Action now urgently required to mitigate climate change has the potential co-benefit of improving air quality and reducing the chronic disease burden. Fossil fuel combustion, primarily from motor vehicles and energy generation, is a major contributor to anthropogenic climate change and air pollution-related health conditions. Action to reduce greenhouse gas emissions by improving energy efficiency, departing from carbon-intensive energy generation, facilitating mass transit and active transport options, also has the potential for significant public health benefits.
\end{abstract}

The first evidence of severe adverse health effects caused by ambient air pollution came from studies in the early twentieth century, which showed a relationship between episodes of extremely elevated concentrations of air pollution and elevated morbidity and mortality. The London smog episode of December 1952, which resulted in about 4000 excess deaths, ${ }^{1}$ led to the modern era of research into the effects of air pollution on human health. At present, a large body of evidence demonstrates that air pollution, even at concentrations below the current air quality standards, is associated with adverse health effects in humans. ${ }^{2-5}$ Climate change is expected to cause a decline in air quality. ${ }^{6}$ The good news is that action on climate change has the potential to reduce levels of air pollutants, resulting in significant public health benefits.
Air pollution is a complex chemical mixture whose effects on the individual can vary in time and place, making it difficult to differentiate between the effects of individual pollutants. The most common outdoor air pollutants in Australia that are relevant to health are: particulate matter (of varying size); ground-level ozone; oxides of nitrogen; carbon monoxide; and sulphur dioxide. There is an Australian Ambient Air Quality (AAQ) National Environment Protection Measure (NEPM) for many, but not all, of these pollutants. National Environment Protection Measures are legally binding standards for each level of government. Each jurisdiction is required to monitor and report performance in relation to the standards.

\section{Particulate matter}

Particulate matter (PM) includes airborne solid or liquid particles including dust, pollens, soot and aerosols from combustion activities. The most common measure of particulate air pollution is the routinely monitored $\mathrm{PM}_{10}$ (particles with a diameter less than $10 \mu \mathrm{m}$ ) in the ambient air. However in the past decade, interest has shifted towards the fine particle fraction of $\mathrm{PM}_{10}, \mathrm{PM}_{2.5}$ (particles with a diameter less than $2.5 \mu \mathrm{m}$ ), as particles of this size are able to penetrate deeper into the lungs and have the potential to be more damaging. In Australia, there is an air National Environment Protection Measure for $\mathrm{PM}_{10}$, however, unlike the United States of America (USA), there is only an advisory reporting standard for $\mathrm{PM}_{2.5}$. Advisory reporting standards do not have a time frame for compliance, and are used to gather data nationally to review the case for adoption of a compliance standard in the future.

\section{Ozone}

Ozone is a secondary pollutant formed, in the presence of sunlight, from the reaction of volatile organic compounds (emitted by the burning of fuels and evaporation from vegetation) and oxides of nitrogen (emitted by burning of fuels). Hot, dry weather conditions are conducive to ozone formation: it is sometimes called summer smog. Ozone is routinely monitored at ground level and has an enforceable National Environment Protection Measure.

This article will concentrate on ambient particulate matter and ozone as these are the most well researched air pollutants and their concentrations are most likely to be of increasing concern under climate change scenarios. ${ }^{6}$ 


\section{How does air pollution contribute to chronic disease?}

There is an extensive literature on the cardiorespiratory impacts of ambient air pollution, reporting a wide range of adverse health outcomes including exacerbation of chronic respiratory and cardiovascular disease, increased risk of cancer and premature mortality (Table 1$)^{7,8}$

Sensitivity to the effects of air pollution differs according to individual susceptibility, age, and pre-existing health conditions. Young children, elderly people, those with chronic cardiac disease, and chronic respiratory disease such as asthma and chronic obstructive pulmonary disease, are generally more likely to be affected. ${ }^{9}$

There is good evidence that ambient air pollution can trigger the acute symptoms of, and exacerbate, both cardiac and respiratory disease. Recent evidence has supported a causal link between the development of asthma in children and exposure to traffic air pollution as well as the exacerbation of established asthma. ${ }^{8,10-12}$ However, at present there is insufficiently strong evidence to support a causal association for chronic disease in all instances.

Plausible biological mechanisms supported by experimental evidence exist whereby air pollution has the potential to cause cardiovascular disease, ${ }^{13}$ through, for example, contributing to a chronic inflammatory state increasing the risk of coronary atherosclerosis. ${ }^{14}$ However more populationbased research is needed to confirm this hypothesis.

\section{Particulate matter}

Increased particle concentrations in ambient air have been associated with long-term effects on mortality as well as increased risks for admissions for cardiac and respiratory disease, including chronic obstructive pulmonary disease, pneumonia and ischaemic heart disease. ${ }^{15}$ In children particulate air pollution has been associated with increased chronic cough, and bronchitis. ${ }^{16}$ Globally, ambient PM air pollution has been estimated to be responsible for at least 0.8 million premature deaths and 6.4 million lost life years. ${ }^{17}$

Pope et al. ${ }^{18}$ in the USA found that each $10 \mu \mathrm{g} / \mathrm{m}^{3}$ elevation in ambient fine particulate air pollution was associated with approximately a $4 \%, 6 \%$ and $8 \%$ increased risk of allcause, cardiopulmonary and lung cancer mortality, respectively. Chen and Goldberg ${ }^{19}$ reviewed 17 cohort studies and 20 case-control studies published 1950-2007 and found a $6 \%$ increase in non-accidental mortality for every increase of $10 \mu \mathrm{g} / \mathrm{m}^{3}$ in ambient fine particles, independent of age, gender and geographical regions. They then estimated that exposure to fine particles would lead to approximately 5000 deaths a year in Canada. Among these deaths, 1100 deaths would be from lung cancer and 2700 deaths would be from cardiovascular diseases. Kunzli et al. ${ }^{20}$ estimated the impact of total ambient air pollution on public health in Austria, France and Switzerland as a total mortality of $6 \%$, or more than 40000 attributable cases a year. About half of this pollution was attributed to motor vehicle traffic.

\section{Ozone}

Ozone exposure can cause lung inflammation resulting in decreased lung function and symptoms of respiratory irritation even in healthy people. It can also exacerbate bronchitis, emphysema and asthma. ${ }^{21}$ The effects of long-term ozone exposure have until recently not been clear, but they may contribute to chronic lung disease, ${ }^{21,22}$ and there is recent evidence of adverse effects on respiratory mortality. ${ }^{23}$

\section{Australia}

In Australia, significant associations have also been found between mortality and ambient air pollution. ${ }^{24,25}$ A study investigating the health effects of air pollution on daily mortality in Brisbane, Melbourne, Perth and Sydney found the strongest associations with particulate matter, nitrogen dioxide and ozone. For example, a $10 \mu \mathrm{g} / \mathrm{m}^{3}$ elevation in $\mathrm{PM}_{2.5}$ concentration was associated with approximately a $1 \%$ increase in the daily total number of deaths. ${ }^{26}$

Respiratory morbidity has been reported in association with outdoor air pollution in a number of Australian regions including the La Trobe Valley, ${ }^{27}$ the Newcastle and Wollongong areas of New South Wales (NSW) ${ }^{5}$ and the Melbourne region. ${ }^{28}$

\section{What is the link between air quality and climate change? \\ Common sources of air pollutants and greenhouse gases}

An important connection between climate change and ambient air quality is that greenhouse gas emissions which drive climate change, and the pollutants described earlier, frequently stem from common sources: primarily fossilfuel combustion. The most important greenhouse gases emitted by carbon-intensive energy generation and motor vehicle use are carbon dioxide $\left(\mathrm{CO}_{2}\right)$, methane $\left(\mathrm{CH}_{4}\right)$ and nitrous oxide $\left(\mathrm{N}_{2} \mathrm{O}\right)$ (Figure 1). Ozone, also a greenhouse gas, can be formed near combustion sources, depending on the meteorological conditions. Fossil fuel combustion also results in the emission of the main ambient air pollutants affecting health which include particulate matter $\left(\mathrm{PM}_{2.5}\right.$ and $\left.\mathrm{PM}_{10}\right)$, ozone $\left(\mathrm{O}_{3}\right)$, sulphur dioxide $\left(\mathrm{SO}_{2}\right)$, nitrogen dioxide $\left(\mathrm{NO}_{2}\right)$ and carbon monoxide (CO) (Table 1).

\section{Interconnection between meteorological variables and ambient air pollution levels}

Greenhouse gases have an effect on climate which in turn has an effect on air pollutant levels, ${ }^{29}$ because factors like 


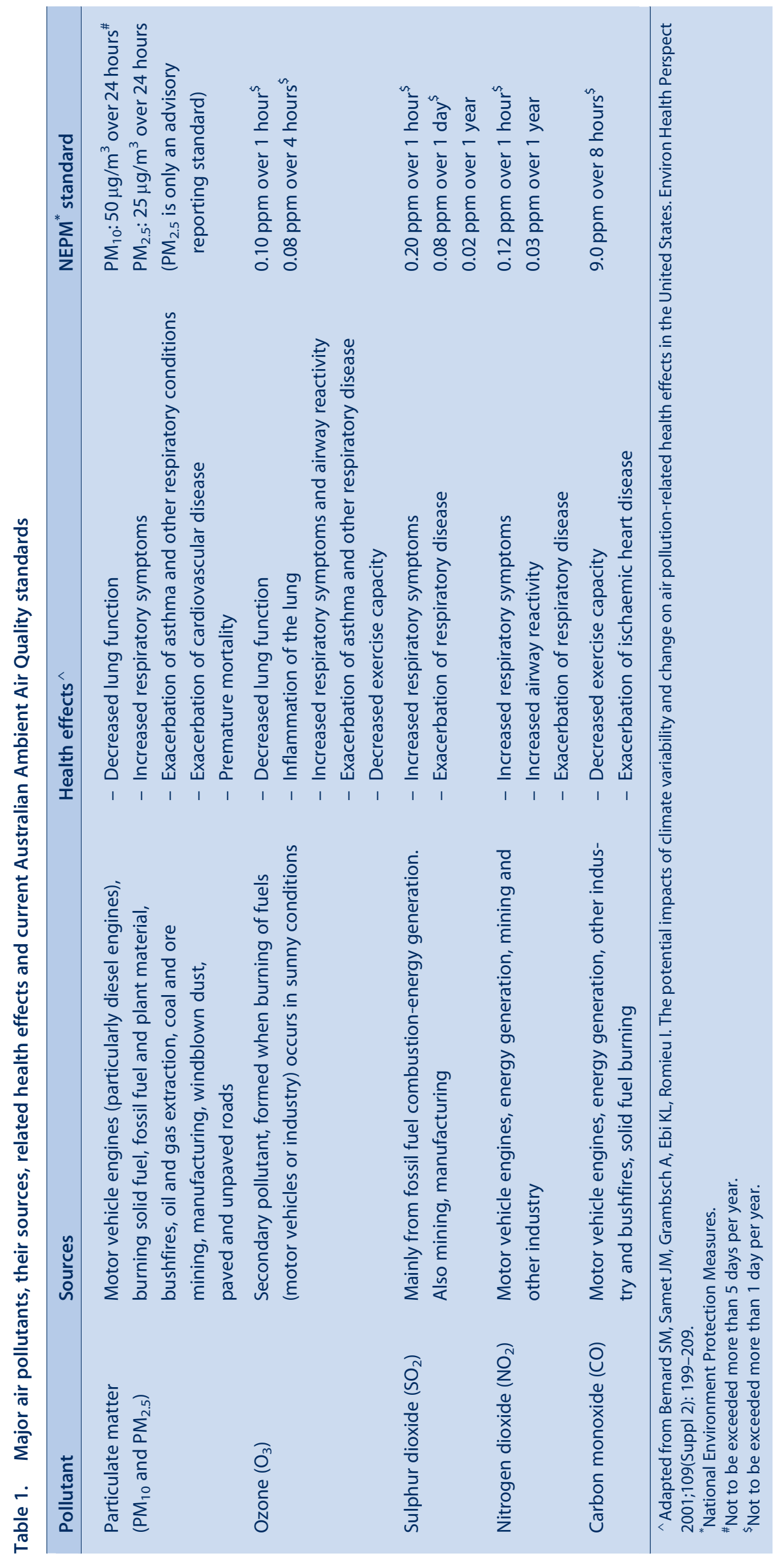


temperature, humidity, wind and precipitation can affect air pollutant emission, chemistry, deposition and transport. ${ }^{30}$ Climate change may enhance the adverse effects of ambient air pollutants due to chemical and physical interactions in the atmosphere. Adverse effects of ozone have been observed during the warmer seasons with evidence of synergistic effects between high temperature and ozone. Similar interactions between effects of ambient PM and temperature have been reported. ${ }^{31}$ Ozone in the troposphere can also act as a powerful greenhouse gas.

The interaction between increasing temperature and ambient air pollution in relation to health effects has also been found in Australia. For example, a study of temperature, air pollution and total mortality in summers in Sydney over the period 1994-2004 found that maximum temperature and sulphur dioxide air pollution had significant interactive effects on mortality. ${ }^{32}$ Temperature has also been found to modify the health effects of particulate matter in Brisbane. ${ }^{33}$ Furthermore, modelled effects of climate change in south eastern Australia predict that increasing bushfire risks will result in increasing levels of fine particles and volatile organic compounds. ${ }^{34}$

\section{Emissions from transport sources}

According to National Greenhouse Gas Inventory data for 2007, motor vehicle transport was responsible for $14.6 \%$ of greenhouse gas emissions in Australia. ${ }^{35}$ Transport emissions are also a major source of ambient air pollutants affecting health. A 2005 Australian Department of Transport working paper found motor vehicles were the principal source of nitrogen oxides and carbon monoxide in capital city airsheds (the geographical boundary for air quality standards), and that a high proportion of motor vehicle particulate emissions were very fine particles. ${ }^{36}$ The motor vehicle share of $\mathrm{PM}_{10}$ in capital city airsheds was $43 \%$ for Sydney, $31 \%$ for Brisbane, $33 \%$ for Melbourne, 19\% for Adelaide, 20\% for Perth and 10\% for Hobart. The same study estimated that in the year 2000, motor-vehicle-related ambient air pollution accounted for between 900 and 2000 premature deaths in Australia. ${ }^{36}$

In Melbourne it is estimated that motor-vehicle emissions are responsible for $80 \%$ of the carbon monoxide, $60 \%$ of the nitrogen oxides, $40 \%$ of the volatile organic compounds and $30 \%$ of particulate matter in the outdoor air. ${ }^{37}$

\section{Emissions from energy generating sources}

In Australia 53.9\% of greenhouse gas emissions come from stationary energy combustion (2007 data). ${ }^{35}$ Of the electricity generated in Australia, $81 \%$ is generated from coal, $13 \%$ from natural gas, $5 \%$ from hydro and $1 \%$ from other sources (including oil and wind). ${ }^{39}$ Electricity generation in Victoria, NSW region (includes the Australian Capital Territory) and Queensland is mainly fuelled by coal. In Western Australia, South Australia and the Northern

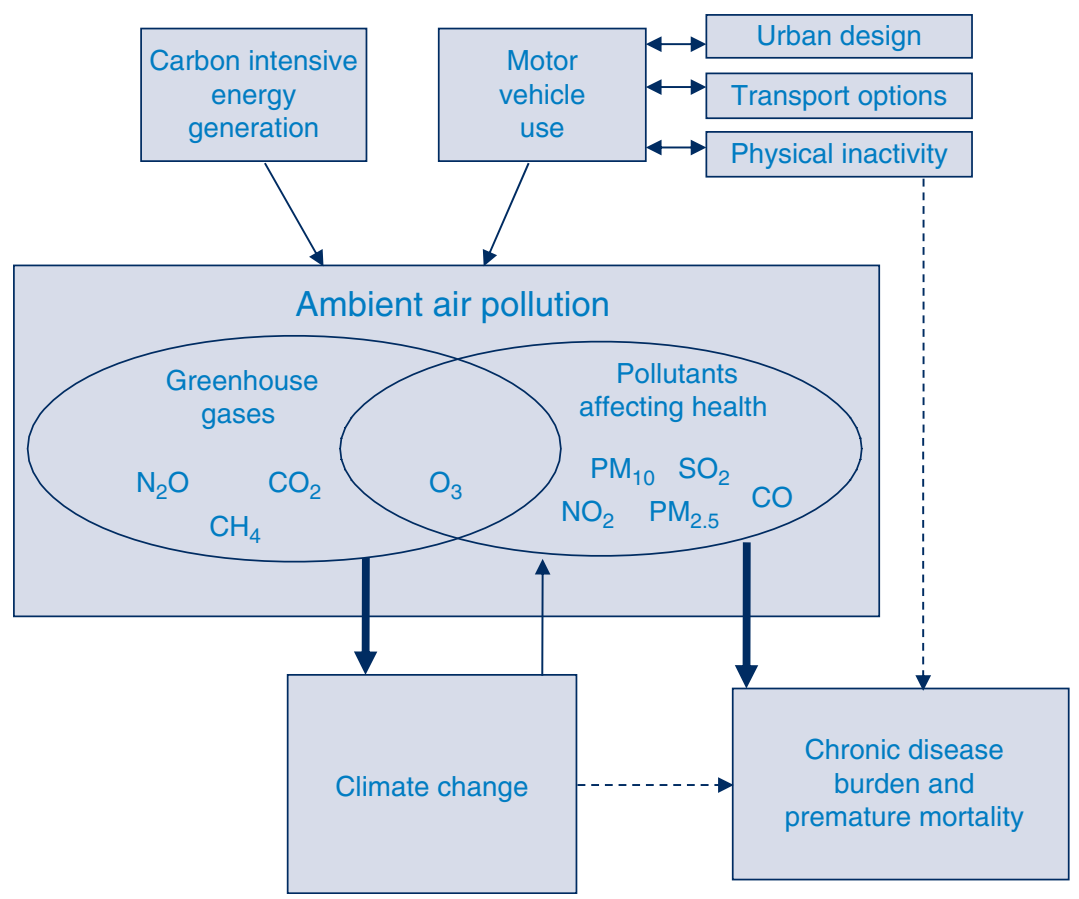

Figure 1. Schematic representation of the interconnections between climate change, air pollution ${ }^{*}$ and chronic disease.

${ }^{*} \mathrm{CH}_{4}$ (methane), $\mathrm{CO}$ (carbon monoxide), $\mathrm{CO}_{2}$ (carbon dioxide), $\mathrm{NO}_{2}$ (nitrogen dioxide), $\mathrm{N}_{2} \mathrm{O}$ (nitrous oxide), $\mathrm{O}_{3}$ (ozone), $\mathrm{PM}_{10}$ (particles with a diameter less than $10 \mu \mathrm{m}$ ), $\mathrm{PM}_{2.5}$ (particles with a diameter less than $2.5 \mu \mathrm{m}$ ), $\mathrm{SO}_{2}$ (sulphur dioxide). 
Territory most electricity is generated by natural gas. Tasmania uses mostly hydrogeneration. ${ }^{39}$

Electricity generation and industrial production are major sources of $\mathrm{PM}_{2.5}$ and $\mathrm{PM}_{10}$ emissions in Australia, often more so outside capital city airsheds. ${ }^{38,40}$ For example, in the Sydney metropolitan airshed, industry contributes to $37 \%$ of $\mathrm{PM}_{10}$ emissions, but if the NSW Greater Metropolitan Region is considered (which includes the Newcastle and Wollongong regions as well as the greater Sydney region), $62 \%$ of $\mathrm{PM}_{10}$ emissions are from industry, primarily coal mining. ${ }^{40}$

Why would action to mitigate climate change help reduce the burden of chronic disease?

Policies that aim to reduce the rate of climate change by reducing greenhouse gas emissions are likely to produce a mutual benefit for health and the environment by reducing health-damaging ambient air pollutants and the related chronic cardiac and respiratory disease burden. While to date in Australia these two problems have been addressed by separate policies, to achieve the best outcome for climate and health, integrating them would be more effective. ${ }^{41}$

Figure 1 shows the interconnections between climate change, ambient air pollution and chronic disease. Action to mitigate climate change can potentially reduce the chronic disease burden because of decreasing air pollutant concentrations affecting health, increasing physical activity as an alternative to vehicle use ${ }^{42-44}$ and reducing the risk of other climate change-related impacts such as heatwaves, bushfires and dust storms.

\section{Transport}

Policies that aim to reduce motor vehicle use by increasing the use of alternative transport, and active transport such as walking and cycling, are also likely to reduce the risk of chronic non-communicable diseases such as obesity, cardiovascular disease and diabetes. ${ }^{45}$

Woodcock et al. used comparative risk assessment methods to estimate the benefits of alternative transport scenarios for London and Delhi, modelling health effects of ambient $\mathrm{PM}_{2.5}{ }^{43}$ The scenario with the largest health gains for London (combined increased active travel and loweremission motor vehicles) produced an estimated 10-19\% reduction in the number of years-of-life lost from ischaemic heart disease, as well as reductions in cerebrovascular disease, depression, dementia and diabetes. This outcome did require large increases in distances walked and cycled and a $37 \%$ reduction in car use. The authors concluded that important health gains and reductions in $\mathrm{CO}_{2}$ emissions could be achieved through replacement of urban trips in private motor vehicles with active travel. However to achieve this level of health benefit, effective policies to increase distances walked and cycled and reduce car use are needed, with creation of safe and attractive urban environments for mass active travel.

Ozone standards have been exceeded every year since 1994 in the Sydney region, with levels sometimes reaching as much as double the standards. ${ }^{40}$ Since 1998, there has been no improvement in levels of ambient ground-level ozone in greater metropolitan Sydney. ${ }^{40}$ Despite improvements with fuel and vehicle emissions standards, the number of vehicles on the road has increased. Around a third of the car trips made in Sydney are less than $3 \mathrm{~km}$ and more than half are less than $5 \mathrm{~km} .{ }^{34}$ Increasing the proportion of these short trips that are walked or cycled could have significant health and climate benefits.

Examples, such as the 1996 Olympic Games in Atlanta, illustrate what can be achieved relatively quickly. Traffic restrictions were put in place for the Games along with increased availability of alternative transport. During this time, peak daily ambient ozone concentrations decreased approximately $30 \%$ from baseline, which was associated with a significantly lower rate of asthma events. ${ }^{46}$

\section{Energy generation}

Modelling by Markandya et al. ${ }^{44}$ of changes in electricity production to reduce $\mathrm{CO}_{2}$ emissions with concomitant reductions in $\mathrm{PM}_{2.5}$ showed health gains in all countries studied, although gains were greatest in developing countries. Changes of modes of electricity generation were estimated to reduce not only carbon dioxide emissions but also particulate air pollution and consequently mortality. They predicted that by pursuing a climate target solely for electricity generation, 104 life-years per million people would be saved every year in the European Union (48 000 in total).

In Australia, major sources of pollution from energy generation and coal mining are often outside of capital city airsheds, e.g. Newcastle, Wollongong and the Latrobe Valley. However changes to these industries to reduce greenhouse gas emissions still have the potential to reduce the health impact on the local population.

\section{Conclusions}

Ambient air pollution is a significant contributor to both climate change and chronic disease. Effective policy needs to incorporate and understand the synergies between climate change and air pollution and the resulting health impacts. Moving away from carbon-intensive energy generation and motor vehicle dependence has the potential to reduce greenhouse gas emissions and the risk of harmful climate change. This action is necessary not only to reduce the range and severity of impacts from climate change, but 
also to reduce the morbidity and mortality that continues to be associated with poor air quality.

\section{References}

1. Logan WPD, Glasg MD. Mortality in London fog incident, 1952. Lancet 1953; 261: 336-8. doi:10.1016/S0140-6736(53)91012-5

2. Brunekreef B, Dockery DW, Krzyzanowski M. Epidemiological Studies on short-term effects of low levels of major ambient air pollution components. Environ Health Perspect 1995; 103(Suppl 2): 3-13. doi:10.2307/3432443

3. Pope CA, Bates DV, Mark E. Health Effects of Particulate Air Pollution: Time for Reassessment. Environ Health Perspect 1995; 103: 472-80. doi:10.2307/3432586

4. Abramson MJ, Beer T. Something particular in the air we breathe? Med J Aust 1998; 169: 452-3.

5. Lewis PR, Hensley MJ, Wlodarczyk J, Toneguzzi RC, WestleyWise VJ, Dunn T et al. Outdoor air pollution and children's respiratory symptoms in the steel cities of New South Wales. Med J Aust 1998; 169: 459-63.

6. Kinney P. Climate change, air quality, and human health. Am J Prev Med 2008; 35: 459-67. doi:10.1016/j.amepre.2008.08.025

7. Bernard SM, Samet JM, Grambsch A, Ebi KL, Romieu I. The potential impacts of climate variability and change on air pollution-related health effects in the United States. Environ Health Perspect 2001; 109(Suppl 2): 199-209. doi:10.2307/ 3435010

8. HEI Panel on the Health Effects of Traffic-Related Air Pollution. Traffic-Related Air Pollution: A Critical Review of the Literature on Emissions, Exposure, and Health Effects. HEI Special Report 17. Boston, MA: Health Effects Institute, 2010.

9. Abelsohn A, Stieb D, Sanborn MD, Weir E. Identifying and managing adverse environmental health effects: 2. Outdoor Air Pollution. CMAJ 2002; 166(9): 1161-7.

10. Clark NA, Demers PA, Karr CJ, Koehoorn M, Lencar C, Tamburic L et al. Effect of early life exposure to air pollution on development of childhood asthma. Environ Health Perspect 2009; 118: 284-90. doi:10.1289/ehp.0900916

11. Gilmour MI, Jaakkola MS, London SJ, Nel AE, Rogers CA. How exposure to environmental tobacco smoke, outdoor air pollutants, and increased pollen burdens influences the incidence of asthma. Environ Health Perspect 2006; 114: 627-33. doi:10.1289/ehp.8380

12. Balmes JR. Can traffic-related air pollution cause asthma? Thorax 2009; 64: 646-7. doi:10.1136/thx.2009.116418

13. Brook RD, Franklin B, Cascio W, Hong Y, Howard G, Lipsett M et al. Expert Panel on Population and Prevention Science of the American Heart Association. Air pollution and cardiovascular disease: a statement for healthcare professionals from the expert panel on Population and Prevention Science of the American Heart Association. Circulation 2004; 109: 2655-71. doi:10.1161/ 01.CIR.0000128587.30041.C8

14. Routledge HC, Ayres JG, Townend JN. Why cardiologists should be interested in air pollution. Heart 2003; 89: 1383-8. doi:10.1136/heart.89.12.1383

15. Pope CA, Dockery DW. Health effects of fine particulate air pollution: lines that connect. J Air Waste Manag Assoc 2006; 56: $1368-80$.
16. Dockery DW, Speizer FE, Stram DO, Ware JH, Spengler JD, Ferris BG, Jr. Effects of inhalable particles on respiratory health of children. Am Rev Respir Dis 1989; 139: 587-94.

17. Cohen AJ, Ross Anderson H, Ostro B, Pandey KD, Krzyzanowski M, Künzli N et al. The global burden of disease due to outdoor air pollution. J Toxicol Environ Health A 2005; 68: 1301-7. doi:10.1080/15287390590936166

18. Pope CA, 3rd, Burnett RT, Thun MJ, Calle EE, Krewski D, Ito K et al. Lung cancer, cardiopulmonary mortality, and long-term exposure to fine particulate air pollution. JAMA 2002; 287 : 1132-41. doi:10.1001/jama.287.9.1132

19. Chen H, Goldberg MS. The effects of outdoor air pollution on chronic illness. Mc Gill J Med 2009; 12: 58-64.

20. Künzli N, Kaiser R, Medina S, Studnicka M, Chanel O, Filliger P et al. Public-health impact of outdoor and traffic-related air pollution: a European assessment. Lancet 2000; 356: 795-801. doi:10.1016/S0140-6736(00)02653-2

21. U.S. EPA. Air Quality Criteria for Ozone and Related Photochemical Oxidants (2006 Final). U.S. Environmental Protection Agency, Washington, DC, EPA/600/R-05/004aF-cF, 2006.

22. U.S. EPA. Provisional Assessment of Recent Studies on Health and Ecological Effects of Ozone Exposure. U.S. Environmental Protection Agency, Washington, DC, EPA/600/R-09/101, 2009.

23. Jerrett M, Burnett RT, Pope CA, 3rd, Ito K, Thurston G, Krewski D et al. Long-term ozone exposure and mortality. NEngl J Med 2009; 360: 1085-95. doi:10.1056/NEJMoa0803894

24. Morgan G, Corbett S, Wlodarczyk J, Lewis P. Air pollution and daily mortality in Sydney, Australia, 1989 through 1993. Am J Public Health 1998; 88: 759-64. doi:10.2105/AJPH.88.5.759

25. Kjellstrom T, Neller A, Simpson R. Air pollution and its health impacts: the changing panorama. Med J Aust 2002; 177: 604-8.

26. Simpson R, Williams G, Petroeschevsky A, Best T, Morgan G, Denison L et al. The short-term effects of air pollution on daily mortality in four Australian cities. Aust N Z J Public Health 2005; 29: 205-12. doi:10.1111/j.1467-842X.2005. tb00758.x

27. Voigt T, Bailey M, Abramson M. Air pollution in the Latrobe Valley and its impact upon respiratory morbidity. Aust NZJ Public Health 1998; 22: 556-61. doi:10.1111/j.1467-842X.1998.tb01438.x

28. EPA Victoria 2001. EPA publication 789 - Ambient Air Pollution and Daily Hospital Admissions in Melbourne 1994-1997.

29. Jacob DJ, Winner DA. Effect of climate change on air quality. Atmos Environ 2009; 43: 51-63. doi:10.1016/j.atmosenv.2008. 09.051

30. Ebi KL, McGregor G. Climate change, tropospheric ozone and particulate matter, and health impacts. Environ Health Perspect 2008; 116: 1449-55. doi:10.1289/ehp.11463

31. Ayres JG, Forsberg B, Annesi-Maesano I, Dey R, Ebi KL, Helms PJ et al. Environment and Health Committee of the European Respiratory Society. Climate change and respiratory disease: European Respiratory Society Position Statement. Eur Respir J 2009; 34: 295-302. doi:10.1183/09031936.00003409

32. Hu W, Mengersen K, McMichael A, Tong S. Temperature, air pollution and total mortality during summers in Sydney 19942004. Int J Biometeorol 2008; 52: 689-96. doi:10.1007/ s00484-008-0161-8 
33. Ren C, Tong S. Temperature modifies the health effects of particulate matter in Brisbane, Australia. Int J Biometeorol 2006 51: 87-96. doi:10.1007/s00484-006-0054-7

34. NSW Government. Department of the Environment, Climate Change and Water. Let's clear the air. Trends and projections. Available at: http://www.cleartheair.nsw.gov.au/science_and_ research/trends_and_projections.aspx (Accessed 1 March 2010.)

35. Department of Climate Change. National Greenhouse Gas Inventory (2009). DCC, Canberra. National Inventory. Available at: http://www.climatechange.gov.au/climate-change/ $\sim /$ media/publications/ greenhouse-report/national-greenhousegas-inventory-pdf.ashx (Accessed 27 April 2010.)

36. Commonwealth of Australia Bureau of Transport and Regional Economics (BTRE). Department of Transport and Regional Services, Working Paper 63: Health impacts of transport emissions in Australia: economic costs. 2005.

37. EPA Victoria. Motor vehicle emissions and air quality. Available at: http://www.epa.vic.gov.au/air/vehicles/ vehicle_emissions.asp (Accessed 1 March 2010.)

38. The National Pollutant Inventory (NPI). Available at: http:// www.npi.gov.au/ (Accessed 1 March 2010.)

39. Energy Supply Association of Australia (ESAA) Limited (2009). The energy industry in Australia. Available at: http://www.esaa.com.au/images/stories/FactSheets/2009facts.pdf (Accessed 27 April 2010.)

40. Department of the Environment \& Climate Change NSW. Current and projected air quality in NSW. A technical paper supporting the Clean Air Forum 2007. Sydney.
Available at: http://www.environment.nsw.gov.au/air/cpairq ual.htm (Accessed 27 April 2010.)

41. Swart R, Amann M, Raers F, Tuinstra W. A good climate for clean air: linkages between climate change and air pollutants. Clim Change 2004; 66: 263-9. doi:10.1023/B:CLIM. 0000044677.41293 .39

42. Smith KR, Jerrett M, Anderson HR, Burnett RT, Stone V, Derwent $R$ et al. Public health benefits of strategies to reduce greenhouse-gas emissions: health implications of short-lived greenhouse pollutants. Lancet 2009; 374: 2091-103. doi:10.1016/ S0140-6736(09)61716-5

43. Woodcock J, Edwards P, Tonne C, Armstrong BG, Ashiru O, Banister D et al. Public Health benefits of strategies to reduce greenhouse-gas emissions: urban land transport. Lancet 2009; 374: 1930-43. doi:10.1016/S0140-6736(09)61714-1

44. Markandya A, Armstrong BG, Hales S, Chiabai A, Criqui P, Mima $S$ et al. Public health benefits of strategies to reduce greenhouse-gas emissions: low-carbon electricity generation. Lancet 2009; 374: 2006-15. doi:10.1016/S0140-6736(09)61715-3

45. National Heart Foundation of Australia, National Stroke Foundation of Australia (2008). Time for Action - National plan to reduce the burden of cardiovascular disease. Available at: http:// www.heartfoundation.org.au (Accessed 27 April 2010.)

46. Friedman MS, Powell KE, Hutwagner L, LeRoy GM, Tegue WG. Impact of changes in transportation and commuting behaviours during the 1996 Summer Olympic Game in Atlanta on air quality and childhood asthma. JAMA 2001; 285: 897-905. doi:10.1001/jama.285.7.897

\section{NSW PUBLIC HEALTH BULLETIN}

\begin{tabular}{|c|c|c|}
\hline $\begin{array}{l}\text { The NSW Public Health Bulletin is a peer-reviewed } \\
\text { ournal produced by the NSW Department of } \\
\text { Health and indexed in Medline. It has a NSW } \\
\text { focus, however, it aims to support the practice of } \\
\text { oublic health more broadly. } \\
\text { Editor } \\
\text { Or Lynne Madden } \\
\text { BSC(Med)Hons1, MBBS, MPH, MSc, FFPH, FAFPHM } \\
\text { Editorial Manager } \\
\text { Mary Sinclair } \\
\text { Editorial correspondence } \\
\text { Please address all correspondence and } \\
\text { submissions to: } \\
\text { The Editor, NSW Public Health Bulletin } \\
\text {-ocked Mail Bag } 961 \\
\text { Vorth Sydney NSW } 2059 \text { Australia } \\
\text { Email: phbulletin@doh.health.nsw.gov.au } \\
\text { Telephone: +61 } 294245876 \\
\text { Fax: +61 } 293919232\end{array}$ & $\begin{array}{l}\text { Submission of articles } \\
\text { The Bulletin accepts proffered and } \\
\text { commissioned articles along with short } \\
\text { reports, on all aspects of public health. } \\
\text { Articles should be 1500-2000 words, not } \\
\text { including tables and figures, and should } \\
\text { include an abstract of up to } 100 \text { words. } \\
\text { Articles should follow the journal style and } \\
\text { layout as closely as possible, as described } \\
\text { in the Instructions to Authors. Articles } \\
\text { should be emailed in a Word for Windows } \\
\text { format to: phbulletin@doh.health.nsw.gov.au, } \\
\text { and should be accompanied by a covering } \\
\text { letter signed by all authors and a License to } \\
\text { Publish. The Instructions to Authors, } \\
\text { License to Publish and other useful } \\
\text { information can be downloaded from the } \\
\text { Bulletin website. }\end{array}$ & $\begin{array}{l}\text { Distribution } \\
\text { The Bulletin is freely available from the } \\
\text { Bulletin website. Copies of the current issue } \\
\text { and back issues can be downloaded in } \\
\text { both PDF and HTML formats. If you would like } \\
\text { to be notified when new issues of the Bulletin } \\
\text { are available online, subscribe to the early } \\
\text { alert email system at the Bulletin website. The } \\
\text { early alert email contains the contents of each } \\
\text { new issue along with electronic links to the } \\
\text { articles. To receive a printed copy of the Bulletin, } \\
\text { subscribe online at the Bulletin website, or } \\
\text { contact your local public health unit or the } \\
\text { editorial office. } \\
\text { elSSN } 1834-8610 \\
\text { Website: www.publish.csiro.au/journals/phb } \\
\text { Copyright c } 2010 \text { NSW Department of Health }\end{array}$ \\
\hline
\end{tabular}

